\title{
Calycosin regulates glucocorticoid-induced apoptosis via Nrf2/ARE signaling in MC3T3-E1 cells
}

\author{
Lifeng Fu' ${ }^{1}$, WeiLiang $\mathrm{Wu}^{2}$, Jian $\mathrm{Zhu}^{2}$, Shu Qiang ${ }^{2}$, Jansong Chen ${ }^{2 \star}$ \\ ${ }^{1}$ Department of Orthopaedics, Hospital of Traditional Chinese Medicine, Keqiao District, Shaoxing, Zhejiang 312030 , \\ ${ }^{2}$ Department of Orthopaedics, Children's Hospital, School of Medicine, Zhejiang University, Zhejiang 310000, PR China
}

*For correspondence: Email: jsongchen@163.com

Sent for review: 18 October 2017

Revised accepted: 12 January 2018

\begin{abstract}
Purpose: To determine the anti-osteoporotic effect of calycosin (CA) and investigate the mechanism involved.

Methods: To establish a cell model of osteoporosis, MC3T3-E1 cells were treated with dexamethasone (DEX). Subsequently, the levels of accumulated reactive oxygen species (ROS) and subsequent apoptotic cell death (using flow cytometry) were determined. Relevant mRNA and protein expression levels were measured by quantitative reverse transcription polymerase chain reaction (qRT-PCR) and immunoblot respectively.

Results: CA reduced the apoptosis and accumulation of ROS in DEX-treated cells. DEX induced the expression of caspase-3/-8/-9 in the cleavage of poly ADPQribose polymerase (PARP), whereas CA treatment decreased expression levels of caspase-3/-8/-9 and PARP. In addition, DEX treatment significantly suppressed the expression of nuclear factor-erythroid 2-related factor 2 (Nrf2) as well as its downstream targets, viz, heme oxygenase-1 and quinone oxidoreductase-1. Interestingly, CA treatment reversed this suppressive effect. It was also found that Nrf2 small interfering RNA effectively inhibited the protective effects of $C A$ against $D E X$ IInduced ROS overproduction as well as apoptosis.

Conclusion: CA attenuates the cytotoxicity of DEX via inhibition of the generation of ROS and promotion of Nrf2 expression. These findings offer novel insights into a molecular approach to the treatment of glucocorticoid-induced osteoporosis via the application of natural compounds.
\end{abstract}

Keywords: Calycosin, Osteoporosis, Nrf2, Antioxidant response elements, Apoptosis

\begin{abstract}
This is an Open Access article that uses a funding model which does not charge readers or their institutions for access and distributed under the terms of the Creative Commons Attribution License (http://creativecommons.org/licenses/by/4.0) and the Budapest Open Access Initiative (http://www.budapestopenaccessinitiative.org/read), which permit unrestricted use, distribution, and reproduction in any medium, provided the original work is properly credited.

Tropical Journal of Pharmaceutical Research is indexed by Science Citation Index (SciSearch), Scopus, International Pharmaceutical Abstract, Chemical Abstracts, Embase, Index Copernicus, EBSCO, African Index Medicus, JournalSeek, Journal Citation Reports/Science Edition, Directory of Open Access Journals (DOAJ), African Journal Online, Bioline International, Open-J-Gate and Pharmacy Abstracts
\end{abstract}

\section{INTRODUCTION}

Osteoporosis is a threat to health, particularly in postmenopausal women [1]. Osteoporosis is characterized by imbalance in the processes of bone formation and resorption, resulting in degenerative bone mineral density and deteriorative bone microarchitecture, which eventually lead to loss of bone strength and an increased risk of fracture [2]. Normal process of bone metabolism largely rely on the dynamic equilibrium between bone formation and bone 
resorption. Osteoclasts and osteoblasts have been reported to play a vital role in maintaining normal bone mass in bony remodeling [3]. The destruction of osteoblasts causes reduced bone formation and imbalanced bone metabolism. Glucocorticoids (GCs) are known to induce osteoporosis, primarily by suppressing osteoblast-mediated osteogenesis [4,5]. In this research, a cell model of osteoporosis was established by treating osteoblasts with a synthetic GC dexamethasone (DEX).

Calycosin (CA) is a compound isolated from Radix astragali (Figure 1), referred as Huangqi in Chinese, which is widely used in traditional medicine in China. In traditional Chinese medicine, Qi is involved in vital substances that contribute to the physiological functions of organs and meridians. Specifically, Huangqi has been widely used to tonify Qi [6-8] and is reported to have a protective effect in postmenopausal women who suffer from osteoporosis [9]. Additionally, total flavones of astragalus extract have also been shown to increase the BMD of ovariectomized rats [10]. However, the effect of CA, which is one of the flavones in Radix astragali, on osteoporosis remains unclear. Therefore, the aim of the present study was to investigate the therapeutic effect of CA in bone loss-associated diseases in post-menopausal women.<smiles>COc1ccc(-c2coc3cc(O)ccc3c2=O)cc1O</smiles>

Figure 1: Chemical structure of calycosin

\section{EXPERIMENTAL}

\section{Cell culture}

MC3T3-E1 osteoblastic cell line (Shanghai Cell Bank, Chinese Academy of Sciences) was cultured in a-Modified Eagle's Medium (MEM) (Gibco, USA), supplemented with $10 \%$ fetal bovine serum (Thermo Fisher Scientific, USA) at $37^{\circ} \mathrm{C}$ in a $5 \% \mathrm{CO}_{2}$ humidified atmosphere.

\section{Assessment of cell viability}

To study the potential effects of CA on MC3T3E1 cells, different concentrations of CA (20 and $80 \mu \mathrm{M})$ were used to pre-treat the cells $\left(1 \times 10^{5}\right.$ cells $/ \mathrm{cm}^{2}$ ) for 2 hrs at $37^{\circ} \mathrm{C}$. Subsequently, DEX $(10 \mu \mathrm{M}$, Sigma-Aldrich, USA) was mixed with the culture medium and incubated for $24 \mathrm{hrs}$. A Cell
Counting Kit (CCK)-8 kit (beyotime, China) was utilized to measure the cell viability described by Huang et al [11]. Then, $4 \times 10^{3}$ cells were dispersed in each well of a 96-well plate and cultured for 6, 12, 24 and 48 hrs respectively. Each well was dispersed with CCK-8 reagent $1 \mathrm{~h}$ prior to the incubation. Then, a microplate reader (BD Biosciences, USA) was utilized to measure the optical density at $450 \mathrm{~nm}$ wavelength. All the parallel experiments were repeated for $>3$ times.

\section{Measurement of apoptosis frequency}

The apoptosis rate of cells were evaluated using an Annexin V-FITC apoptosis detection kit (KeyGEN Biotech, China). MC3T3-E1 cells were harvested after treatment of DEX for $24 \mathrm{hrs}$, the mixture was washed with ice-cold 1xPBS buffer and re-suspended in $500 \mu \mathrm{L}$ binding buffer. After addition of $5 \mu \mathrm{L}$ Annexin $\mathrm{V}$ stock solution, the mixture was incubated at $4{ }^{\circ} \mathrm{C}$ for $10 \mathrm{~min}$. FACSCalibur flow cytometer (BD Biosciences, USA) was utilized to analyze immediately following the addition of $5 \mu \mathrm{L}$ propidium iodide.

\section{Determination of ROS}

Flow cytometric analysis was applied to detect ROS levels in cells as described previously [12]. After incubating with dihydrorhodamine 123 (0.5 $\mu \mathrm{M}$; Sigma-Aldrich, USA) at $37^{\circ} \mathrm{C}$ for $0.5 \mathrm{hrs}$, the MC3T3-E1 cells were washed with 1xPBS and re-suspended in complete medium. After this treatment, the fluorescent intensity was assessed by a flow cytometry (Ex, 490 nm; Em, 520 nm).

\section{qRT-PCR analysis}

TRIzol reagent (Gibco; Thermo Fisher Scientific) was utilized to separate Total RNA from the cells. RT-qPCR analysis was completed on an $A B I$ 7500 thermal cycler (Applied Biosystems), and $20 \mathrm{ng}$ template RNA was used in a $25 \mu \mathrm{L}$ reaction volume with $2 x \operatorname{SYBR}^{\circledR}$ Green PCR Master mix (Thermo Fisher Scientific, USA) and gene specific primer pairs. CDNA was synthesized at $55{ }^{\circ} \mathrm{C}$ for $30 \mathrm{~min}$ following manufacture's protocol. qRT-PCR cycles were stated in Table 1. $2^{-\Delta \Delta C t}$ value was adopted to quantify relative mRNA expression levels of the target genes, compared to GAPDH [13].

Table 1: qRT-PCR cycle

\begin{tabular}{lccc}
\hline Variable & $\begin{array}{c}\text { Temperature } \\
\left({ }^{\circ} \mathbf{C}\right)\end{array}$ & Time & Cycle \\
\hline Pre-denaturation & 94 & $2 \mathrm{~min}$ & 1 \\
Denaturation & 94 & $15 \mathrm{~s}$ & 40 \\
Annealing & 60 & $30 \mathrm{~s}$ & \\
Extension & 68 & $50 \mathrm{~s}$ & \\
Extension & 68 & $5 \mathrm{~min}$ & 1 \\
\hline
\end{tabular}

Trop J Pharm Res, February 2018; 17(2): 206 
Table 2: Primers for RT-qPCR analysis

\begin{tabular}{|c|c|c|c|}
\hline Variable & Forward & Reverse & $\begin{array}{c}\text { Product } \\
\text { length }\end{array}$ \\
\hline Nfr2 & $\begin{array}{c}5^{\prime}- \\
\text { TTCCTCTGCTGCCATTAG } \\
\text { TCAGTC-3' }\end{array}$ & $\begin{array}{c}\text { 5'- } \\
\text { GCTCTTCCATTTCCGAGTCA } \\
\text { CTG-3' }\end{array}$ & 215 bps \\
\hline $\begin{array}{l}\text { Heme oxygenase-1 } \\
\text { (HO1) }\end{array}$ & $\begin{array}{c}\text { 5'- } \\
\text { ATCGTGCTCGCATGAAC } \\
\text { ACT-3' }\end{array}$ & $\begin{array}{c}\text { 5'CCAACACTGCATTTACATG } \\
\text { GC-3' }\end{array}$ & 339 bps \\
\hline $\begin{array}{l}\text { NAD(P) H: quinone } \\
\text { oxidoreductase-1 } \\
\text { (NQO1) }\end{array}$ & $\begin{array}{c}\text { 5'- } \\
\text { ACTCGGAGAACTTTCAGT } \\
\text { ACC-3' }\end{array}$ & $\begin{array}{c}5^{\prime}- \\
\text { TTGGAGCAAAGTAGAGTGG } \\
\text { T-3' }\end{array}$ & 492 bps \\
\hline GAPDH & $\begin{array}{c}\text { 5'- } \\
\text { ATCACTGCCACCCAGAA } \\
\text { G-3' }\end{array}$ & $\begin{array}{c}\text { 5'- } \\
\text { TCCACGACGGACACATTG-3' }\end{array}$ & 191 bps \\
\hline
\end{tabular}

\section{Immunoblot analysis}

Cells were washed twice with 1xPBS buffer, then lysed in RIPA buffer (Beyotime, China) containing $1 \%$ protease inhibitor cocktail (PIC) (Sigma-Aldrich, USA). The supernatant of the cell lysates was collected, and the protein concentrations were measured via BCA assay (Thermo Fisher Scientific, USA). Proteins (20-30 $\mu g)$ were separated by $10-12 \%$ SDSpolyacrylamide gels, which were transferred onto polyvinylidene fluoride membranes (Millipore, USA). After blocking, membranes were incubated with primary antibodies including anticaspases -3, -8, and -9 (1:1000; catalog nos. ab2171, ab25901 and ab52298; Abcam, UK), anti- PARP (1:1000; catalog no. ab4830; Abcam, UK), anti-Nrf2 (1:1000; catalog no. PA5-19830; Invitrogen, USA), anti-HO1 (1:1000; catalog no. MA1-112; Invitrogen, USA), anti-NQO1 (1:1000; catalog no. 39-3700; Invitrogen, USA), and antiGAPDH (1:1500; catalog no. MA5-15738; Invitrogen, USA) for $1 \mathrm{~h}$ at room temperature. After wash with 1xPBS buffer, membranes were subsequently incubated with goat anti-mouse (catalog no. A23610) or goat anti-rabbit (catalog no. A23620) secondary HRP antibody (1:1000; Beyotime, China) for $45 \mathrm{~min}$ at $22{ }^{\circ} \mathrm{C}$. Bands were developed using enhanced chemiluminescence (ECL) (Thermo Fisher Scientific, USA) and quantified by densitometry analysis of Quantity One ${ }^{\circledR}$ 1-D Analysis software (V. 4.6.8; Bio-Rad, USA).

\section{RNA interference}

To achieve a confluence of $60-80 \%$ confluence, $2 \times 10^{5}$ MC3T3-E1 cells per well were seeded and cultured overnight. The silencing assay was performed according to manufacturer's protocol, with a Nrf2 small interfering (si) RNA assay kit that contained a pool of three 19-25 nucleotide target-specific Nrf2 siRNAs (catalog no. sc-37049; Santa Cruz Biotechnology, USA). Expression levels of Nrf2 and its downstream targets, i.e., $\mathrm{HO} 1$ and NQO1, were measured using immunoblot analysis.

\section{Statistical analysis}

SPSS (version 16.0, IBM, USA) was applied to analyze the experimental results. One-way analysis of variance (ANOVA) was performed. Type of post-hoc test is dependent on whether the variances are homogeneous (LSD) or heterogeneous (Dunnett T3). Statistical significant difference was set at a threshold of $p$ $<0.05$.

\section{RESULTS}

\section{Effect of CA on cell viability}

To investigate the effects of CA on cell proliferation, a CCK-8 assay was performed (Figure 2). We observed that $>20 \mu \mathrm{M}$ doses of $\mathrm{CA}$ significantly increased the viability of the MC3T3-E1 cells at 6, 12, 24, and 48 hrs (Figure 2A). In addition, CA promoted cell proliferation in a dose- and time-dependent way. Hence, 20 and $80 \mu \mathrm{M}$ doses of CA were used in the following studies.

\section{Effect of CA on the DEX-induced apoptosis}

To investigate effects of CA on apoptosis, DEXtreated cells were treated with CA. The results demonstrated that cells viability was significantly suppressed by DEX compared to the untreated group. However, CA significantly increased the viability of the DEX-treated cells in a dose- and time-dependent way (Figure 2 B). Moreover, apoptotic rates of the cells in the control, DEX, CA $20 \mu \mathrm{M}$ and CA $80 \mu \mathrm{M}$ groups were also measured (Figure $3 \mathrm{~A}$ ). Treatment with DEX lead to an apoptotic frequency of $36.42 \%$, compared to $6.84 \%$ in the control group. However, CA decreased the apoptotic frequency to 28.26 (20 $\mu \mathrm{M})$ and $14.35 \%(80 \mu \mathrm{M})$. Therefore, $\mathrm{CA}$ 
A

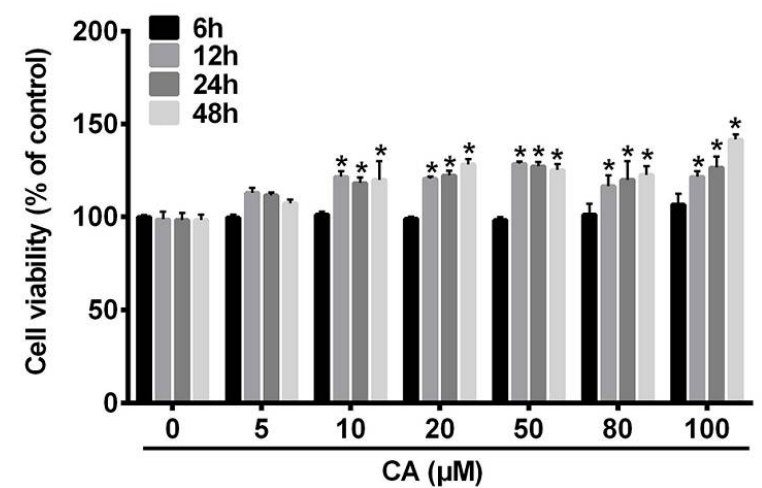

B

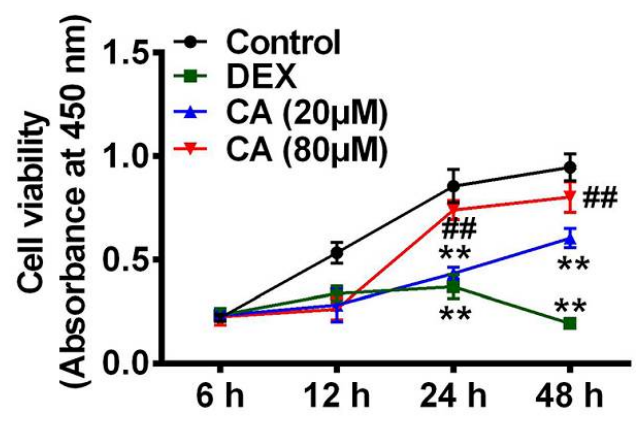

Figure 2: Effect of CA on MC3T3-E1 cell viability. (A) Cells were exposed to CA (concentrations at 0, 5, 10, 20, $50,80$, and $100 \mu \mathrm{M})$ for $6,12,24$ and $48 \mathrm{~h}$, then CCK8 assay was used to ascertain the cell viability. (B) Different doses of CA $(0,20$ and $80 \mu \mathrm{M})$ were used to treat the cells for $2 \mathrm{~h}$. Treated cells were then exposed to DEX for 24 h. Cell viability was quantified by a CCK8 assay. (Error bar: mean $\pm S D ; n=6 ;{ }^{\#} p<0.01$, vs. the untreated group; $p<0.05, \quad p<0.01$, vs. the DEX-treated group). Abbreviations: CA, calycosin; DEX, dexamethasone

A

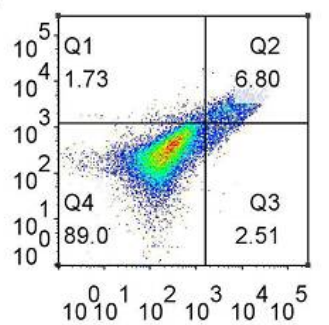

B

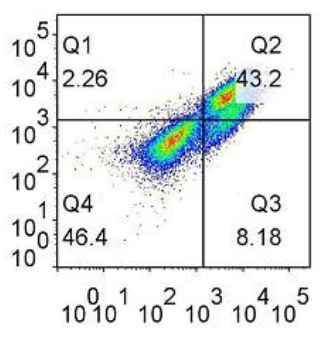

C
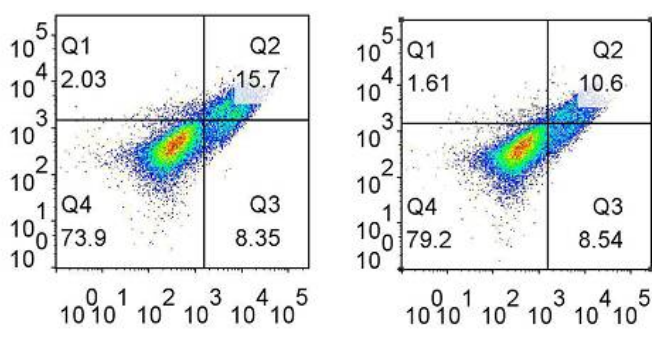

$\mathrm{C}$

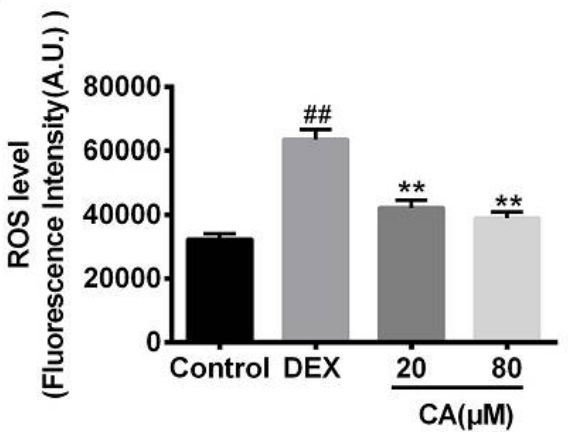

Figure 3: Effects of CA on ROS and apoptotic levels in DEX- treated cells. (A) Cells were treated with series of doses of CA $(0,20$ and $80 \mu \mathrm{M})$ for $2 \mathrm{~h}$, followed by $24 \mathrm{~h} \mathrm{DEX}$ exposure. Apoptosis was measured using Annexin $V$ assay. (B) ROS levels, determined by flow cytometry. (Error Bar: mean $\pm S D ; n=6$; ${ }^{\#} p<0.01$, vs. the untreated group; " $p<0.01$, vs. the DEX-treated group). Abbreviation: CA, calycosin; DEX, dexamethasone

exhibited a protective effect against apoptosis upon DEX treatment.

\section{Effect of CA on ROS production following DEX treatment}

As shown in Figure $3 \mathrm{C}$, ROS levels were significantly increased following $24 \mathrm{~h}$ of DEX treatment, as compared to control group levels. However, treatment with 20 and $80 \mu \mathrm{M} \mathrm{CA}$ effectively reduced the higher ROS level observed in the DEX-treated group.

\section{Effect of CA on caspase-3/-8/-9 and PARP expression levels}

The immunoblot analysis showed the levels of caspase-3/-8/-9 increased dramatically in DEX treated MC3T3-E1 cells (Figure 4 A-B), suggesting DEX-induced apoptosis was mediated by mitochondria and/or death receptor. However, CA treatment $(20$ and $80 \mu \mathrm{M})$ significantly suppressed the DEX-induced activation and upregulation of caspases $(-3,-8$ and -9 ) in a dose-dependent way of the inhibition occurred simultaneously. In addition, DEX treatment resulted in PARP cleavage (Figure 4). 
A

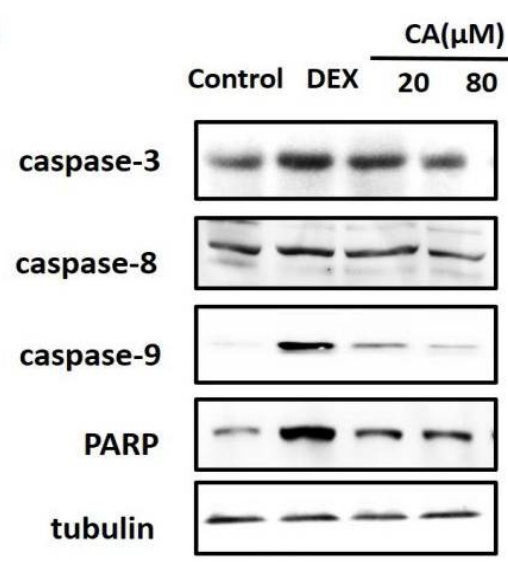

B

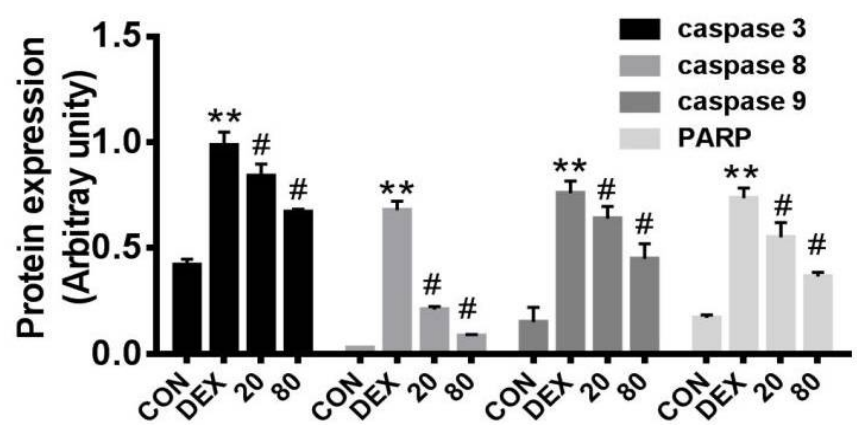

Figure 4: Effect of CA on caspase-3/-8/-9 and PARP expression levels. Cells were treated with different doses of CA $(0,20$ and $80 \mu \mathrm{M})$ for $2 \mathrm{~h}$, followed by $12 \mathrm{~h}$ of DEX exposure. (A) Caspase-3/-8/-9 and PARP expression levels were quantified using immunoblot. $(B)$ Quantification of the Western blot results. (Error Bar: mean $\pm S D ; n$ = 6; ${ }^{\# \#} p<0.01$, vs. the untreated group; ${ }^{* *} p<0.01$, vs. the DEX-treated group). Abbreviation: CA, calycosin; DEX, dexamethasone. PARP, poly (ADP-ribose) polymerase

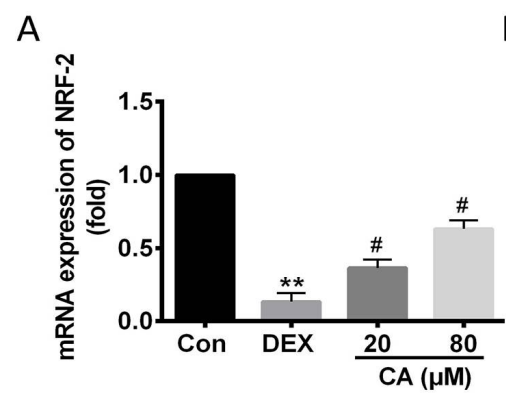

D
B

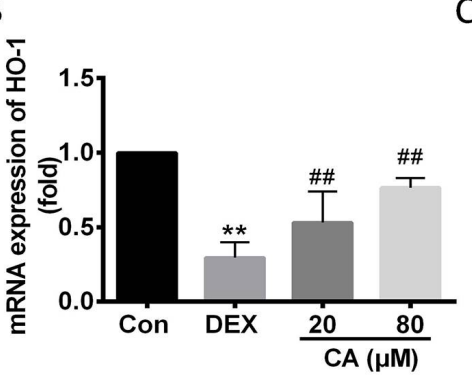

$E$

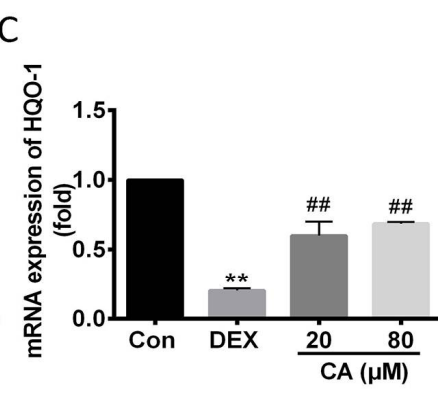

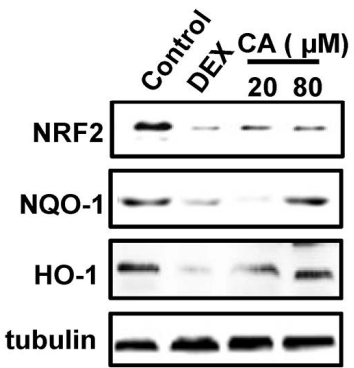

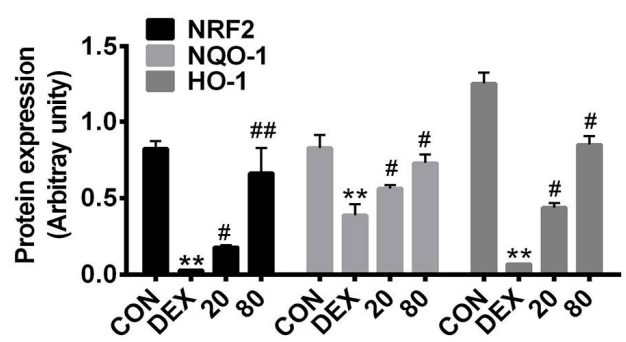

Figure 5: Effect of CA on Nrf2 and its downstream targets. Levels of mRNA expression of (A) Nrf2, (B) NQO1 and (C) HO1. (D) Protein expression levels of Nrf2, NQO1 and HO1. (E) Quantification of protein expression. (Error Bar: mean $\pm \mathrm{SD} ; \mathrm{n}=6$; \#\#p $<0.01$, vs. the untreated group; ${ }^{\star \star} p<0.01$, vs. the DEX-treated group). Abbreviation: CA, calycosin; DEX, dexamethasone

As expected, this cleavage was suppressed by the addition of CA $(20$ and $80 \mu \mathrm{M})$. Taken together, the results demonstrated that $\mathrm{CA}$ inhibited apoptosis in osteoblastic cells.

\section{Effect of CA on Nrf2 signaling}

The RT-qPCR and western blot showed DEX treatment suppressed mRNA levels of Nrf2 and its downstream effectors (Figure 5 A-C). However, CA reversed this decrease. As shown in Figure $5 \mathrm{D}$ and $\mathrm{E}$, the expression levels of Nrf2, HO1 and NQO1 were significantly suppressed in DEX-treated MC3T3-E1 cells.
After CA treatment, Nrf2, HO1, and NQO1 expression was effectively recovered, suggesting that CA inhibited the DEX-induced ROS production via Nrf2 signaling activation.

\section{Involvement of Nrf2 pathway in the interactions of DEX and CA}

As the results shown in Figure 6A, Nrf2-siRNA downregulated levels of Nrf2, $\mathrm{HO} 1$ and NQO1, demonstrating Nrf2 silencing was effective. The effects on apoptosis of DEX-induced cell arising from Nrf2-knockdown were also examined. As shown in Figure 6 A-B, CA reduced DEX-induced 
A

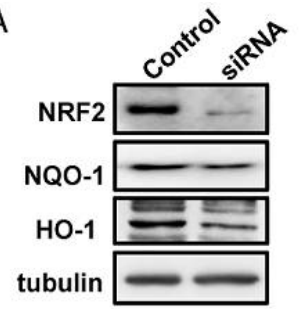

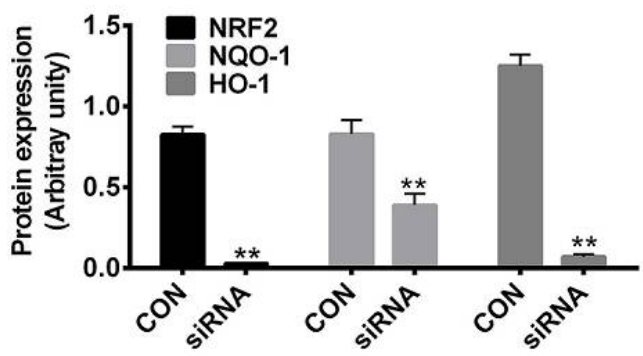

B
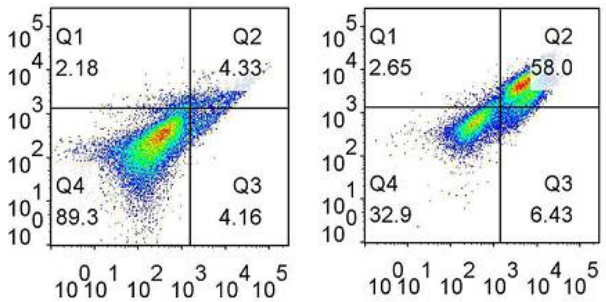

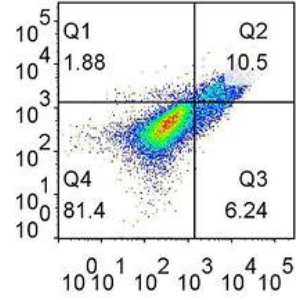

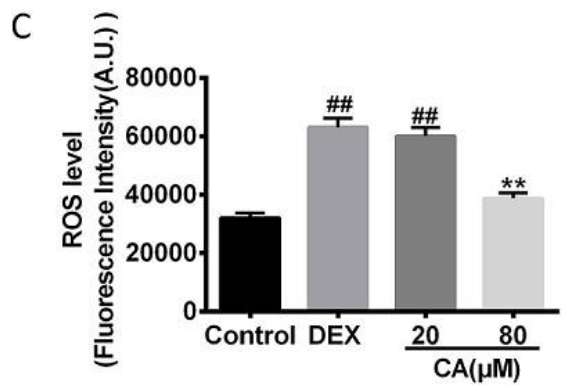

Figure 6: Effect of CA on Nrf2 signaling. (A) Protein levels of Nrf2, HO1 and NQO1 after treatment with siRNANrf2 for $24 \mathrm{~h}$. Effect of CA on apoptosis (B) and ROS levels (C). (Error Bar: mean \pm SD; $n=6$; ${ }^{\# \#} p<0.01$, vs. the untreated group; ${ }^{\star *} p<0.01$, vs. the DEX-treated group). Abbreviation: CA, calycosin; DEX, dexamethasone

apoptosis that resulted from ROS overproduction. In addition, Nrf2-siRNA inhibited the protective effects of CA. Thus, Nrf2 knockdown recovered the DEX-induced cytotoxicity. Supplementation of CA reversed the DEX-induced cell apoptosis from 31 to $11.6 \%$. However, Nrf2 siRNA increased the apoptotic rate of MC3T3-E1 cells to $23.7 \%$. CA reduced the DEX-induced ROS overproduction from 212 $\%$ in the control to $119 \%$, showing a recovery of $93 \%$ (Figure 6C).

\section{DISCUSSION}

$\mathrm{CA}$, a phytoestrogen, is a major active flavonoid in Radix Astragali [14,15], which shows antitumor, antioxidative and anti-osteoporotic abilities [6]. It is reported that calycosin-7-O- $\beta$-Dglucopyranoside inhibits osteoclast development in vitro and bone loss in vivo. Through regulating the bone morphogenetic protein/WNT signaling pathways, calycosin-7-O- $\beta$-D-glucopyranoside can also promote the osteoblastic cell differentiation in ST2 model (16). CA also exerts a protective role in bone loss in ovariectomized rats in a dose-dependent way [17]. Here, we explored the effects of CA on MC3T3-E1 cells upon DEX treatment, a synthetic GC. Our research revealed that $\mathrm{CA}$ promoted cell proliferation in a dose-/time-dependent way. In the DEX -treated cells, CA decreased the apoptosis rate and intracellular levels of ROS. Collectively, CA exhibited protective effects on the DEX-treated MC3T3-E1 cells.

Generation of ROS can cause loss of mitochondrial membrane potential, which ultimately resulting in cell apoptosis. Our data illustrated that the supplementation of CA effectively inhibited the rapid onset and timedependent production of ROS, which is induced by DEX. Our findings demonstrated that CA protected MC3T3-E1 cells from cytotoxicity via inhibiting ROS production. The study also demonstrated downstream effects caused by increased ROS production in osteoblastic cells. Functioning as one of the major regulators of cytoprotective responses, the Nrf2 signaling pathway responds to changes in ROS and electrophiles that are associated with endogenous and exogenous stress [18,19]. Therefore, western blot and qRT-PCR analyses 
are useful methods for determining the effects of DEX treatment on Nrf2 and its downstream genes. These results illustrated that mRNA levels of Nrf2, HO1 and NQO1 were decreased in the DEX-treated MC3T3-E cells. To examine the role of Nrf2 signaling in DEX-induced apoptotic cell death, we analyzed the ability of DEX to induce and the ability of CA to protect against apoptosis using Nrf2-siRNA. The results showed that CA protected against DEX-induced apoptosis and increased ROS levels. These protective effects were significantly decreased by downregulation of Nrf2.

\section{CONCLUSION}

The findings of this study demonstrate that ROSmediated downregulation of Nrf2 contributes to DEX-induced cytotoxicity in MC3T3-E1 osteoblastic cells, and that CA reverses DEXcytotoxicity by inhibiting the accumulation of ROS and promoting the expression of Nrf2. These results provide an insight into potential molecular treatment strategies for DEX-induced osteoporosis using natural compounds.

\section{DECLARATIONS}

\section{Conflict of Interest}

No conflict of interest associated with this work.

\section{Contribution of Authors}

The authors declare that this work was done by the authors named in this article and all liabilities pertaining to claims relating to the content of this article will be borne by them. Lifeng wrote this paper and participated in the study design and experiments, Wei Liang Jian and Zhu Wu performed the experiments and analyzed the data, Jansong Chen and Shu Qiang designed this study and supervised the experiments.

\section{REFERENCES}

1. Tanaka $Y$, Mori $H$, Aoki $T$, Atsumi $T$, Kawahito $Y$, Nakayama $H$, Tohma S, Yamanishi $Y$, Hasegawa $H$, Tanimura $K$, et al. Analysis of bone metabolism during early stage and clinical benefits of early intervention with alendronate in patients with systemic rheumatic diseases treated with high-dose glucocorticoid: Early Diagnosis and Treatment of Osteoporosis in Japan (EDITOR-J) study. J Bone Miner Metab 2016; 34: 646.

2. McCloskey E. A BMD threshold for treatment efficacy in osteoporosis? A need to consider the whole evidence base. Osteoporos Int 2016; 27(1): 417-419.
3. Rosario PW, Carvalho M, Calsolari MR. Symptoms of Thyrotoxicosis, Bone Metabolism, and Occult Atrial Fibrillation in Older Women with Mild Endogenous Subclinical Hyperthyroidism. Clin Endocrinol (Oxf) 2015; 85(1): $132-136$.

4. Yao W, Cheng Z, Busse C, Pham A, Nakamura MC, Lane NE. Glucocorticoid excess in mice results in early activation of osteoclastogenesis and adipogenesis and prolonged suppression of osteogenesis: a longitudinal study of gene expression in bone tissue from glucocorticoid-treated mice. Arthritis Rheum 2008; 58 : 1674-1686.

5. Phillips JE, Gersbach CA, Wojtowicz AM, Garcia AJ. Glucocorticoid-induced osteogenesis is negatively regulated by Runx2/Cbfa1 serine phosphorylation. J Cell Sci 2006; 119: 581-591.

6. Qiu R, Ma G, Zheng C, Qiu X, Li X, Li X, Mo J, Li Z, Liu $Y$, Mo $L$, et al. Antineoplastic effect of calycosin on osteosarcoma through inducing apoptosis showing in vitro and in vivo investigations. Exp Mol Pathol 2014, 97(1): 17-22.

7. Zhou Y, Liu QH, LiU CL, Lin L. Calycosin induces apoptosis in human ovarian cancer SKOV3 cells by activating caspases and Bcl-2 family proteins. Tumour Biol 2015; 36: 5333-5339.

8. Wu J, Xu H, Zhang L, Zhang X. Radix Astragali and Tanshinone Help Carboplatin Inhibit B16 Tumor Cell Growth. Technol Cancer Res Treat 2015; 15(4): 583588.

9. Guo CC, LH Zheng, Fu JY, Zhu JH, Zhou YX, Zeng T, Zhou ZK. Antiosteoporotic Effects of Huangqi Sanxian Decoction in Cultured Rat Osteoblasts by Proteomic Characterization of the Target and Mechanism. EvidBased Compl Alt 2015; (1): 1-10.

10. Cao J, Chen Z, Zhu Y, Li Y, Guo C, Gao K, Chen L, Shi $X$, Zhang $X$, Yang $Z$, et al. Huangqi-Honghua combination and its main components ameliorate cerebral infarction with Qi deficiency and blood stasis syndrome by antioxidant action in rats. $J$ Ethnopharmacol 2014; 155: 1053-1060.

11. Huang J, Sun C, Wang S, He Q, Li D. microRNA miR$10 b$ inhibition reduces cell proliferation and promotes apoptosis in non-small cell lung cancer (NSCLC) cells. Mol Biosyst 2015; 11: 2051-2059.

12. Chen JY, Zhang L, Zhang H, Su L, Qin LP. Triggering of p38 MAPK and JNK signaling is important for oleanolic acid-induced apoptosis via the mitochondrial death pathway in hypertrophic scar fibroblasts. Phytother Res 2014; 28: 1468-1478.

13. Livak KJ, Schmittgen TD. Analysis of relative gene expression data using real-time quantitative PCR and the 2- $\triangle \triangle C T$ method. Methods 2001; 25: 402-408.

14. Zhao XL, Liu L, Di LQ, Li JS, Kang A. Studies on effects of calycosin-7-O-beta-D-glucoside on prim-Oglucosylcimifugin and cimifugin in vivo pharmacokinetics. Zhongguo Zhong Yao Za Zhi 2014; 39: 4669-4674. 
15. Ruan JQ, Yan R. Regioselective glucuronidation of the isoflavone calycosin by human liver microsomes and recombinant human UDP-glucuronosyltransferases. Chem Biol Interact 2014; 220: 231-240.

16. Jian J, Sun L, Cheng $X, H u X$, Liang J, Chen $Y$. Calycosin-7---d-glucopyranoside stimulates osteoblast differentiation through regulating the BMP/WNT signaling pathways. Acta Pharm Sin B 2015; 5: 454-460.

17. Hong W. Experimental study on the effect of Calycosin on prevention and treatment of osteoporosis in ovariectomized rats. Orthop Biomech Mater Clin Study 2010; 07: 11-14.
18. Roy CS, Sengupta $S$, Biswas $S$, Sinha TK, Sen R, Basak RK, Adhikari B, Bhattacharyya A. Bacterial fucose-rich polysaccharide stabilizes MAPK-mediated Nrf2/Keap1 signaling by directly scavenging reactive oxygen species during hydrogen peroxide-induced apoptosis of human lung fibroblast cells. Plos One 9: e113663, 2014.

19. McMahon M, Campbell KH, MacLeod AK, McLaughlin $L A$, Henderson CJ, Wolf CR. HDAC inhibitors increase NRF2-signaling in tumour cells and blunt the efficacy of co-administered cytotoxic agents. Plos One 2014; 9: e114055. 